\title{
Urinary hippuric acid and orthocresol excretion in man during experimental exposure to toluene
}

\author{
M DøSSING, ${ }^{1}$ J B AELUM, ${ }^{2}$ S H HANSEN,${ }^{3}$ G R LUNDQVIST, ${ }^{2}$ AND N T ANDERSEN ${ }^{4}$ \\ From the Medical Department A, ${ }^{1}$ Rigshospitalet, Copenhagen, Institute of Hygiene ${ }^{2}$ University of Aarhus, \\ Royal Danish School of Pharmacy, ${ }^{3}$ Copenhagen, and Department of Theoretical Statistics, ${ }^{4}$ Institute of \\ Mathematics, University of Aarhus, Denmark
}

\begin{abstract}
It is not known whether urinary excretion of hippuric acid (HA) or orthocresol (O-Cr) is to be preferred for the biological monitoring of workers with occupational exposure to toluene. To study this, 42 printing trade workers with more than 10 years' exposure to a mixture of organic solvents including toluene $(0-20 \mathrm{ppm})$ and 43 control subjects matched by age, smoking habits, and living accomodation were investigated. Each matched pair was randomised to an experimental exposure of either $100 \mathrm{ppm}$ or $0 \mathrm{ppm}$ toluene for 6.5 hours under controlled conditions in an exposure chamber. Urinary excretion of $\mathrm{HA}$ and $\mathrm{O}-\mathrm{Cr}$ was determined by high pressure liquid chromatography from samples obtained before exposure, during the first three hours, and during the last 3.5 hours of exposure. No difference in $\mathrm{HA}$ and $\mathrm{O}-\mathrm{Cr}$ excretion was found between printing trade workers and controls. The median $\mathrm{O}-\mathrm{Cr}$ excretion increased 29 times during exposure, whereas the HA excretion increased only five times. Thus only $3 \%$ of the $\mathrm{O}-\mathrm{Cr}$ excretion originated from other sources than toluene whereas the corresponding value for $\mathrm{HA}$ was $19 \%$. Standardisation of the concentrations of $\mathrm{HA}$ and $\mathrm{O}-\mathrm{Cr}$ in relation to urinary creatinine reduced the relative variation by $29 \%$ and $56 \%$ respectively. This was not reduced further by expressing the excretions as average excretion rates based on total volume of urine collected. Background urinary $\mathrm{O}-\mathrm{Cr}$ excretion was three to four times higher among smokers than nonsmokers, probably due to the content of $\mathrm{O}-\mathrm{Cr}$ in cigarettes. The $\mathrm{O}-\mathrm{Cr}$ excretion in unexposed smokers was, however, 10 times lower that that of the non-smokers during the end of the experimental exposure to $100 \mathrm{ppm}$ toluene.
\end{abstract}

The use of urinary metabolite excretion as an index of occupational exposure to organic solvents is suggested by the good correlation between these indices and biological changes. ${ }^{1}$

As a measure of exposure to toluene two urinary metabolites of toluene have received major interest in biological monitoring. Firstly, hippuric acid (HA) because most $(80 \%)$ of the body burden of toluene is metabolised to this substance and, secondly, $\mathrm{o}-\mathrm{Cresol}(\mathrm{O}-\mathrm{Cr})$ because this is regarded as the only known specific metabolite of toluene. ${ }^{2}$ The lack of specificity of HA and the very small proportion of the retained toluene that is excreted as $\mathrm{O}-\mathrm{Cr}$ $(\leqslant 0.1 \%)$ raise the question which of these metabolites is to be preferred in the biological monitoring of people exposed to toluene.

Received 9 July 1982

Accepted 15 December 1982
To investigate the excretion of toluene metabolites in man we have developed highly sensitive high performance liquid chromatographic (HPLC) methods to measure the urinary excretion of HA and $\mathrm{O}-\mathrm{Cr},{ }^{3}$ and an experimental exposure to toluene was set up.

\section{Material and methods}

Eighty five people, 42 male printing trade workers and 43 controls aged 29-50, were included in the study. The printers were selected in collaboration with their trade union from six rotogravure and flexoprinting plants. Only those who had been employed for at least 10 years in printing plants and at least five years at the present plant were included. Workers with known heart, lung, liver, kidney, or any other disabling diseases, or with more than 15 days of absence from work during the past year were 
excluded. Regular use of psychotropics, hypnotics, or analgesics was also used as an exclusion criterion.

The controls were selected from the municipal register of Aarhus, Denmark. A questionnaire was mailed to 300 people who matched the 42 printers, according to age, educational level (skilled or unskilled workers), and living accommodation. From the information gathered in this way the controls were selected as the closest match according to the same criteria as the printing trade workers, except that those with occupational exposure to organic solvents or other potentially harmful chemicals were excluded.

The printers had been exposed to a mixture of organic solvents including toluene. During the last years toluene had gradually been replaced by other solvents including ethylacetate and alcohols. Work room air analyses had been performed on several occasions in all the plants during the past three years. The mean exposure level was 0.48 (range $0 \cdot 1$ to 1.1 ) of the sum of the concentrations divided by the respective maximal allowed time weighted average concentrations (TLV). The concentrations of toluene ranged from 0 to $20 \mathrm{ppm}$ (parts per million). Everyone had been at work the day before the examination, giving an exposure free interval of 15-18 hours for printing trade workers.

The mean age for both printers and controls was 36.4 years. Body height and weight were $178 \mathrm{~cm}$ (range 162-192 cm) and $78 \mathrm{~kg}$ (range $58-105 \mathrm{~kg}$ ) respectively. Sixteen of the printers were nonsmokers, nine were moderate smokers (consumption below 11 cigarettes daily), and 17 were heavy smokers. The corresponding numbers in the control group were 16 , seven, and 20 .

\section{EXPERIMENTAL EXPOSURE}

Each matched pair was randomised to exposure to either 100 or $0 \mathrm{ppm}$ toluene during 6.5 hours in a controlled exposure chamber. Before the experiment everyone gave informed consent and underwent a general medical examination before entering the chamber. The exposure was carried out under the continuous supervision of a physician.

\section{EXPOSURE CHAMBER}

The exposure took place in a climatic chamber with a floor area of $29 \mathrm{~m}^{2}$ and a volume of $83 \mathrm{~m}^{3}$. The walls were of stainless steel, and all the equipment of the chamber was made either of steel or teflon to minimise adsorption of toluene or other vapours.

The chamber was equipped with a recirculation system with a capacity of $1400 \mathrm{~m}^{3} \mathrm{~h}^{-1}$. Conditioned particle and charcoal filtered outdoor air was supplied with a rate of $380 \mathrm{~m}^{3} \mathrm{~h}^{-1}$ corresponding to an air renewal of 4.6 changes $h^{-1}$. The temperature in the room was $22.8 \pm 0.5^{\circ} \mathrm{C}$ (mean $\pm \mathrm{SD}$ ) and the relative humidity was $40 \cdot 2 \pm 1 \cdot 2 \%$.

Toluene vapour (Merck Uvasol art 8331 $(99.7 \%)), 20 \%$ saturated, was led to the fresh air supply. The concentration of toluene in the chamber air was continuously monitored by a flame ionisation detector (Bendix model 8401), which was calibrated daily with a standard gas containing $106 \mathrm{ppm}$ toluene in synthetic air (de Linde, Germany). The concentration of toluene was continually adjusted by changing the degree of saturation of the inlet vapour.

During 6.5 hours of experimental exposure to toluene the concentration was $102 \pm 2 \mathrm{ppm}$ (382 \pm $7 \mathrm{mg} / \mathrm{m}^{3}$ ), and during the control experiment the concentration of hydrocarbons was below $0 \cdot 1 \mathrm{ppm}$.

Three or four people were exposed at a time. The physical activity was moderate. They were usually seated or working lightly in a standing position.

\section{URINE SAMPLING AND ANALYSIS}

Sampling of the total volume of urine was carried out in three consecutive periods before and during exposure. The time of the last micturition before entering the chamber was registered, and the urine was collected before exposure (period -2.5-0 h), after three hours of exposure (period 0-3 h), and at the end of exposure (period 3-6.5 h). The exact time of micturition and the volume of urine were registered, and samples were taken for analysis.

The concentration of hippuric acid (HA) and o-Cresol $(\mathrm{O}-\mathrm{Cr})$ was determined by a HPLC technique described elsewhere. ${ }^{3}$ Detection limits were $0.005 \mathrm{mg} \times \mathrm{ml}^{-1}$ for HA and $0.005 \mu \mathrm{g} \times \mathrm{ml}^{-1}$ for $\mathrm{O}-\mathrm{Cr}$. Concentration of creatinine in urine was determined by the Jaffe method. ${ }^{4}$

\section{STATISTICS}

The statistical comparisons were carried out using analysis of variance techniques (repeated measurement design) after logarithmic transformation. The covariances between the urinary excretion of metabolites and the personal variables age, body height and weight, and consumption of alcohol and tobacco were calculated and the statistical model was adjusted for the influence of the factors correlating significantly to the excretion rates.

The three samples in the four groups were compared using a standard analysis of variance. To investigate the time course of the excretion the differences between the first and the second, and the first and the third samples were analysed using a two dimensional analysis of variance. The calculations were made by the computer system Genstat. ${ }^{5}$ Probability values of less than $5 \%$ were considered statistically significant. 

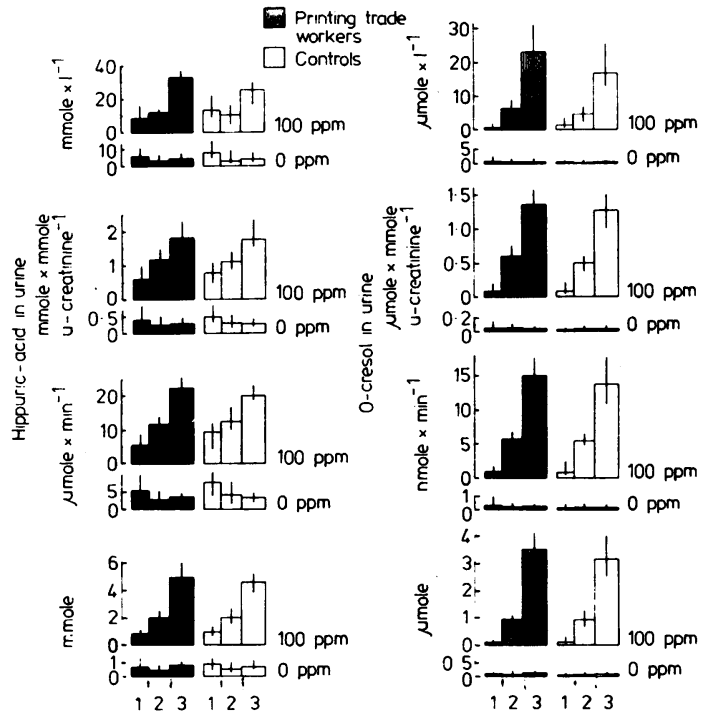

Somple No
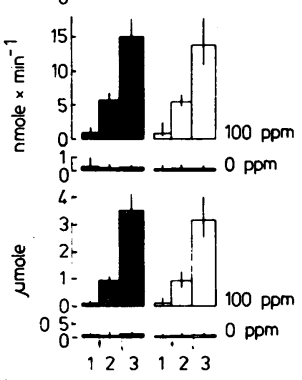

Time course of urinary hippuric acid and $\mathrm{O}-\mathrm{Cr}$ excretion from 43 printing trade workers and 42 controls during experimental exposure to $100 \mathrm{ppm}$ or $0 \mathrm{ppm}$ toluene for 6.5 hours. Excretion is expressed in four ways: at top of figure as a concentration (mole $\times 1^{-1}$ ), below after correction with urinary creatinine (mole $\times$ mole u-creatinine ${ }^{-1}$ ), below again as an excretion rate $\left(\right.$ mole $\times$ min $\left.^{-1}\right)$, and at bottom as an absolute excretion from each of three sampling periods (mole). Sample one covers the period $-2.5-0 \mathrm{~h}$, sample two $0-3 h$, and sample three 3-6.5 h. Each column represents the median with quartiles. Arrows on time axis shows start of exposure to $100 \mathrm{ppm}$ or $0 \mathrm{ppm}$ toluene.

\section{Results}

The urinary excretion of the two metabolites through the experiment is shown in the figure. The median and quartiles are depicted for each of the four groups examined. The urinary excretion is expressed in four different ways: (dimensions in brackets):

(1) The concentration in urine (mole $\times 1^{-1}$ )

(2) The concentration standardised in relation to urinary creatinine (mole $\times$ mole creatinine ${ }^{-1}$ )

(3) The excretion rate $\left(\right.$ mole $\left.\times \min ^{-1}\right)$ and

(4) The absolute quantity excreted in each sampling period (mole).

In the groups exposed to $0 \mathrm{ppm}$ toluene the values of both metabolites were almost constant during the three periods, while a gradual rise in excretion was seen from the first three hours to the last 3.5 hours of exposure.

The standardisation of the concentration of metabolites in relation to urinary creatinine reduced the relative variation of $\mathrm{HA}$ and $\mathrm{O}-\mathrm{Cr}$ by $29 \%$ and $56 \%$ respectively. This coefficient was not reduced further when the excretion was expressed as a rate or as the total quantity.

Only metabolite concentration standardised in relation to urinary creatinine and the excretion rates were analysed for the influence of background variables.

No difference was observed in the pre-exposure level or the excretion during exposure between printers and controls in any of the metabolites, neither during exposure to $100 \mathrm{ppm}$ toluene nor 0 ppm. Moreover, neither age, consumption of alcohol, nor drugs significantly influenced the excretion of $\mathrm{O}-\mathrm{Cr}$ or $\mathrm{HA}$.

The table shows the estimates of $\mathrm{O}-\mathrm{Cr}$ excretion rates in the three samples of non-smokers, moderate smokers, and heavy smokers. As may be seen in the table, smokers had a baseline excretion rate three times higher than non-smokers. In both the groups exposed to $0 \mathrm{ppm}$ and the groups exposed to 100 $\mathrm{ppm}$ this difference remained constant. The relative difference, however, decreased as the excretion rates increased during toluene exposure. The rela-

Geometric mean excretion rate of hippuric acid and o-cresol in non-smokers, moderate smokers ( $\leqq 10$ cigarettes per day), and heavy smokers. Difference between non-smokers and each of the groups of smokers is indicated by an asterisk $\left(^{*} p \leqq\right.$ $0.05,{ }^{* *} p \leqq 0.01$ )

\begin{tabular}{|c|c|c|c|c|c|c|}
\hline & \multicolumn{3}{|c|}{ Groups exposed to 0 ppm $(n=45)$} & \multicolumn{3}{|c|}{ Groups exposed to $100 \mathrm{ppm}(n=40)$} \\
\hline & $\begin{array}{l}\text { Non-smokers } \\
(n=25)\end{array}$ & $\begin{array}{l}\text { Moderate smokers } \\
(n=7)\end{array}$ & $\begin{array}{l}\text { Heavy smokers } \\
(n=13)\end{array}$ & $\begin{array}{l}\text { Non-smokers } \\
(n=7)\end{array}$ & $\begin{array}{l}\text { Moderate smokers } \\
(n=9)\end{array}$ & $\begin{array}{l}\text { Heavy smokers } \\
(n=24)\end{array}$ \\
\hline \multicolumn{7}{|l|}{$\begin{array}{l}\text { Hippuric acid } \\
\left(\mu \text { mole } \times \min ^{-1}\right):\end{array}$} \\
\hline $\begin{array}{l}\text { Before exposure } \\
0-3 \mathrm{~h} \\
3-6.5 \mathrm{~h}\end{array}$ & $\begin{array}{l}5.60 \\
2.57 \\
3.02\end{array}$ & $\begin{array}{l}5.90 \\
3.25 \\
2.97\end{array}$ & $\begin{array}{l}5 \cdot 31 \\
2 \cdot 10 \\
4 \cdot 43\end{array}$ & $\begin{array}{r}4 \cdot 30 \\
9 \cdot 58 \\
18 \cdot 98\end{array}$ & $\begin{array}{r}5.89 \\
11.31 \\
17.75\end{array}$ & $\begin{array}{r}7 \cdot 32 \\
12 \cdot 65 \\
22 \cdot 51\end{array}$ \\
\hline $\begin{array}{l}\text { O-cresol } \\
\left(\text { nmole } \times \min ^{-1}\right) \text { : }\end{array}$ & & & & & & \\
\hline $\begin{array}{l}\text { Before exposure } \\
0-3 \mathrm{~h}\end{array}$ & $\begin{array}{l}0.27 \\
0.28\end{array}$ & $\begin{array}{l}0.84^{* *} \\
0.66\end{array}$ & $1 \cdot 16^{* *}$ & $\begin{array}{r}0.26 \\
4.79\end{array}$ & $0.88^{* *}$ & $\begin{array}{l}0.92^{* *} \\
5.90\end{array}$ \\
\hline $3-6.5 \mathrm{~h}$ & 0.27 & $0.48^{*}$ & $0.92^{*}$ & 14.79 & $14 \cdot 26$ & $16 \cdot 18^{*}$ \\
\hline
\end{tabular}


tive differences between smokers and non-smokers expressed as a concentration of $\mathrm{O}-\mathrm{Cr}$ corrected for urinary creatinine did not differ from the excretion rates.

According to body weight a difference appeared between the two measurements. The rise in the $\mathrm{O}-\mathrm{Cr}$ concentration corrected for urinary creatinine was inversely proportional to the body weight, while no correlation between rate and body weight was observed. In the non-exposed groups no relation between body weight and metabolite excretion was found.

The correlation coefficient ( $r$ ) between total amount of $\mathrm{HA}$ and $\mathrm{O}-\mathrm{Cr}$ excreted during exposure to $100 \mathrm{ppm}$ toluene was $0.52(\mathrm{p} \leqslant 0.001)$ whereas the corresponding coefficient in the non-exposed groups was not significant $(r=0 \cdot 22, p \geqslant 0 \cdot 20)$.

\section{Discussion}

This study shows an increase in the urinary $\mathrm{HA}$ and $\mathrm{O}-\mathrm{Cr}$ excretion during 6.5 hours of experimental exposure to $100 \mathrm{ppm}$ toluene, corresponding to the time weighted average concentration during a working day allowed in most Western countries.

As the relative increase in urinary $\mathrm{O}-\mathrm{Cr}$ excretion both in the first and the second half of the exposure was four times the corresponding rise in $\mathrm{HA}, \mathrm{O}-\mathrm{Cr}$ discriminated better than HA between those nonexposed and those exposed to toluene at the present TLV. If the TLV is lowered to $50 \mathrm{ppm}$ as proposed in Denmark $^{6}$ the difference between the two metabolites will be even more pronounced.

The differences are partly explained by the small amounts of $\mathrm{O}-\mathrm{Cr}$ in the urine of both the printing trade workers and the controls at the start of the experiment, indicating that the exposure free period of about 16 hours from the last occupational exposure to toluene at the levels up to $20 \mathrm{ppm}$ was sufficient to metabolise all the toluene retained during the occupational exposure.

The urinary $\mathrm{O}-\mathrm{Cr}$ levels in the control urine (at time 0 ) and during the exposure were similar to those of previous studies. ${ }^{7-9}$ The background level of HA was somewhat higher than previously described, probably due to dietary factors. ${ }^{9}$ We have observed a significantly-on average more than three times-higher $\mathrm{O}-\mathrm{Cr}$ excretion in the urine of smokers than non-smokers. This has not been reported before and may be caused by the content of $\mathrm{O}-\mathrm{Cr}$ in cigarettes, about $2 \mathrm{mg}$ per 100 cigarettes. ${ }^{10}$ The small amounts of $\mathrm{O}-\mathrm{Cr}$ found in urine of nonsmokers could be caused by passive smoking or $\mathrm{O}-\mathrm{Cr}$ from other sources.

The excretion of HA did not show the same correlation to body weight and smoking habits as $\mathrm{O}-\mathrm{Cr}$.
This may partly be explained by the "noise" from other sources of benzoic acid.

The lack of difference in urinary excretion of HA and $\mathrm{O}-\mathrm{Cr}$ between printers and controls indicates an equal metabolism of toluene in the two groups. Thus the self stimulating effect of toluene on its own metabolism found in animals exposed to $300 \mathrm{ppm}$ could not be found among printers in the present study. " This was probably due to the much lower exposure to toluene in this group, and the fact that the concomitant exposure to other solvents does not alter the metabolism significantly.

The study was supported by the Working Environment Fund, Denmark, and the Danish Medical Research Council (Grants Nos 12-0649 and 123045). We thank the Danish Printers Trade Union and the Employers Association for help with selection of personnel, and are grateful to Michael Vaeth for help in the statistical analyses.

Requests for reprints to: Martin Døssing, Medical Department F, Copenhagen County Hospital in Gentofte, Niels Andersensvej 65, DK $2900 \mathrm{Hel}-$ lerup.

\section{References}

' Lauwerys R. Biological criteria for selected industrial toxic chemicals: a review. Scand J Work Environ Health 1975;1:139-72.

${ }^{2}$ Angerer J. Occupational chronic exposure to organic solvent Int Arch Environ Health 1979;43:63-7.

${ }^{3}$ Hansen SH, Dossing M. Liquid chromatographic determination of urinary hippuric acid and o-cresol as indices of toluene exposure on dynamically modified silica. J Chromatogr 1982;229:141-8.

4 Bonsnes RW, Taussky HH. On colorimetric determination of creatinine by Jaffe reaction. J Biol Chem 1945;158:581-91.

5 Alvey NG. Genstat, a general statistic program. Rothamsted Experimental Station, 1977.

- Arbejdstilsynet. Danish Threshold Limit Values. Copenhagen: Arbejdstilsynet, 1981. (In Danish.)

' Pfáffli P, Savolainen H, Kalliomäki PL, Kalliokoski P. Urinary o-cresol in toluene exposure. Scand $J$ Work Environ Health 1979;5:286-9.

- Woiwode K, Drysch K. Experimental exposure to toluene: further consideration of cresol formation in man. $\mathrm{Br} \mathrm{J}$ Ind Med 1981;38:194-7.

- Veulemans H, Masschelein R. Experimental exposure to toluene III, urinary hippuric acid excretion as a measure of individual solvent uptake. Int Arch Occup Environ Health 1979;43:5362.

${ }^{10}$ Wynder EL, Hoffman D. Tobacco and tobacco smoke. New York and London: Academic Press, 1967: 500.

" Elovaara E, Savolainen H, Pfäfli P, Vaino H. Effects of subacute toluene inhalation on its metabolism and disposition. Arch Toxicol 1979;2:245-8. 